REVISTA ECONOMÍA

Vol. 7I, N. ${ }^{\circ}$ II3 (mayo 2019), IO7-I23

\title{
EL EXTRACTIVISMO EN SUDAMÉRICA: :POR QUÉ NO NOS HA DESARROLLADO? UNA LECTURA DESDE EL ECUADOR
}

\author{
ROMMEL ALVARADO TORRES, ${ }^{\mathrm{I}}$ MARCO POSSO ZUMÁRRAGA, ${ }^{2}$ MARCO POSSO LÓPEZ 3 \\ ${ }^{1}$ Flacso, Ecuador, ${ }^{2,3}$ Universidad Central del Ecuador
}

Recepción de manuscrito: 26 de abril de 2019

Aceptación de versión final: 30 de abril de 2019

\begin{abstract}
RESUMEN El presente artículo establece, desde la perspectiva ecuatoriana, por qué los países extractivistas sudamericanos no se desarrollan a partir de la explotación de sus recursos naturales. Para aquello, se realiza un análisis de la evolución del extractivismo desde la época colonial hasta la actualidad, encontrándose que esta actividad económica se ha intensificado a lo largo de la historia, dejando significativas rentas en todos los países que la practican. Se concluye que los pueblos no se han desarrollado debido principalmente a que los gobiernos no han asignado eficientemente esos ingresos a verdaderos proyectos de inversión y reducción de la desigualdad.
\end{abstract}

PALABRAS CLAVE Recursos naturales, extractivismo, ingresos, desarrollo, desigualdad.

ABSTRACT This article establishes, from the Ecuadorian perspective, why the South American extractivist countries do not develop from the exploitation of their natural resources. For that, an analysis of the evolution of extractivism is made from the colonial period to the present, finding that this economic activity has intensified throughout history, leaving significant income in all the countries that practice it. It is concluded that the villages have not been developed due mainly to the fact that the governments have not efficiently allocated those income to real investment projects and reduction of inequality.

KEYWORDS Natural resources, extractivism, income, development, inequality.

JEL CODES O13, L71, N36, Q3o.

\section{INTRODUCCIÓN}

La utilización y aprovechamiento de la naturaleza por parte de los seres humanos para satisfacer sus múltiples necesidades materiales, data desde el inicio mismo de su existencia, hace miles de años. Al principio, los hombres y mujeres se apropiaban de los recursos que ofrecía la tierra únicamente en pequeñas cantidades, para mantener solo un nivel de vida mínimo capaz de garantizar su permanencia en el planeta. En consecuencia, las tasas de extracción de los bienes y servicios naturales eran menores que las tasas de renovación de los mismos, por lo que los ecosistemas tenían tiempo suficiente para regenerarse y seguir manteniendo el equilibrio ecológico del universo (Alvarado, 2014, pág. 1). 
A partir del aparecimiento histórico de los sistemas socioeconómicos del feudalismo, socialismo y, sobre todo, del capitalismo que surgió en el siglo xvi con el impulso del colonialismo, el mundo empezó a experimentar una serie de profundas transformaciones en todos los aspectos de la vida, por ejemplo, se creyó que el crecimiento económico iba a solucionar todos los problemas sociales y conduciría al desarrollo y bienestar de la población; en este sentido, se intensificó la explotación de los recursos naturales, es decir, se optó por promover un extractivismo $o^{1}$ hasta unas tasas insostenibles y se amplió la capacidad de la gente para elevar el consumo a niveles exagerados e innecesarios.

En el caso de Sudamérica, pensando que los recursos naturales que poseemos son infinitos, se implantó en el imaginario de la gente la idea de que la extracción y apropiación de bienes materiales era lo que nos iba a conducir hacia un mejor bienestar de la sociedad (visión antropocéntrica). ${ }^{2}$ Estas ideas fueron recogidas de los economistas occidentales clásicos como Adam Smith y David Ricardo, pues ellos las presentaron por primera vez en la década de 1770, creyendo que el desarrollo económico de una nación consistía únicamente en la acumulación de capital en base en la abundante producción y libre comercialización de mercancías en los mercados internacionales (Pacheco, 2004).

La teoría neoclásica, de su parte, que surgió más tarde en la década de 1870, además de la acumulación de capital, define también al desarrollo económico como el aumento de acervo de tecnología (Prats, 2006). La teoría keynesiana divulgada en la década de 1930, concibe al desarrollo económico como una medida de la capacidad que tiene un país para alcanzar el pleno empleo de la población. Para conseguir este objetivo, considera que la intervención del Estado en la economía a través del gasto público es fundamental (Primera y Gregorio, 2013, pág. 126).

Estos postulados, clásicos, neoclásicos y keynesianos, sobre el desarrollo no dieron resultado en América Latina y el Caribe porque fueron pensados para los países desarrollados de Europa occidental, por lo que Raúl Prebisch, sin alejarse de la noción materialista del desarrollo considerada por los autores anteriores, en la década de 1940, conceptualizó un modelo de progreso y bienestar para la región, en donde relacionó al desarrollo económico con el aumento de la cantidad de fábricas locales, para que manufacturen los bienes que están siendo importados (Pacheco, 2004). Es importante indicar que este modelo también fracasó.

La teoría neoliberal, cuyo origen se da en la década de 1970, entiende el desarrollo económico como la expansión del capital financiero, el cual brota a merced de menos intervención del Estado en la economía, más participación privada, desregulación de los mercados, libre competencia entre las empresas y libre comercio de mercancías (Herrera, 2006).

Como se puede evidenciar, todas estas concepciones de desarrollo se han fundamentado en el aumento de la renta per cápita, promovido por una creciente extracción de recursos naturales para su posterior transformación en bienes finales. No obstante, hoy en día, luego de comprobar que no se puede seguir creciendo indefinidamente porque el planeta Tierra tiene límites físicos para dar bienes y recibir desechos (Meadows, Meadows y Randers, 1994), y como una respuesta al abuso que estamos cometiendo contra la naturaleza al sobreexplotar sus recursos para sostener un sistema económico autodestructor y obstáculo para el progreso de los países pobres como lo es el capitalismo (Primera y Gregorio, 2013, pág. 131), están empezando a emerger con ímpetu varios estudiosos de la academia proponiendo nuevas alternativas 
y concepciones de lo que debería ser el desarrollo, así como también distintas percepciones del rol que deben cumplir los seres humanos, la naturaleza y la cultura dentro del proceso.

Gudynas (2012), por ejemplo, critica severamente las actividades extractivas y sostiene que el desarrollo, en vez de estar orientado al «crecimiento económico» —crecimiento del producto interno bruto (PIB) - basado en la extracción de recursos naturales, debe conceptualizarse en términos de «crecimiento social, cultural o político» (pág. 22). Los grupos feministas, de su parte, afirman que si bien el desarrollo debe buscar el bienestar socioeconómico, también debe promover el cuidado medioambiental en equidad de género, sin violencia y explotación humana (visión biocéntrica); ${ }^{3}$ pero, sobre todo, debe priorizar la «descolonización y despatriarcalización» (Aguinaga, Lang, Mokrani y Santillana, 2012, págs. 55-56).

Desde el punto de vista de los derechos humanos, Sen (2012, pág. 55) traspasa el enfoque materialista y financiero y propone una visión más integral, en la que considera a las personas como el verdadero objeto del desarrollo, afirmando que éste debe ser definido como un proceso que no promueva solamente la expansión económica, sino también la expansión de las libertades de la gente, tales como la capacidad de poder evitar la desnutrición y la mortalidad prematura; la capacidad de leer, de expresarse o relacionarse; la capacidad de acceder a la salud y educación, etcétera. Coraggio (2004, citado en Acosta, 2005) de su parte, indica que el desarrollo «es un proceso sin fin, que puede implicar pasar por etapas de consumismo [...], o bien, dando un gran salto, llegar a otro estilo de vida más austero pero pleno de posibilidades para el desarrollo de las personas y sus relaciones» (pág. 66).

Desde la perspectiva de la ecología, se han planteado también varios enfoques de desarrollo. Por ejemplo, el «desarrollo sostenible» propone a nivel mundial lograr de manera equilibrada el desarrollo económico y social sin destruir el medio ambiente, de tal modo de satisfacer las necesidades de las generaciones presentes sin poner en riesgo la capacidad de las generaciones futuras para satisfacer también sus propias necesidades (Organización de las Naciones Unidas, ONU, 2018). En el caso de Ecuador, ya se aplica el concepto de «crecimiento verde», el cual busca que las empresas realicen una producción más limpia orientada al cuidado del medio ambiente (Ministerio del Ambiente, 2018).

Por lo tanto, ante las nuevas concepciones de desarrollo y los numerosos rechazos que ha recibido el extractivismo de parte de activistas sociales, personajes políticos e intelectuales académicos, principalmente en la primera década del siglo XXI, el presente artículo se elabora con el objetivo de dar a conocer cómo ha evolucionado en el Ecuador esta actividad económica desde la época colonial hasta la actualidad, qué problemas socioeconómicos y socioambientales ha generado realmente, por qué no se ha constituido en el motor propulsor del desarrollo de los ecuatorianos y qué alternativas se han planteado para prescindir de él y pasar hacia una nueva etapa postextractivista de mejor bienestar individual y colectivo.

\section{DEL EXTRACTIVISMO COLONIAL AL NEOEXTRACTIVISMO}

La colonización de los europeos en otros continentes constantemente estuvo motivada por la apropiación de los recursos naturales que poseían los territorios conquistados. En América, por ejemplo, continente inmensamente rico en acervo de bienes y servicios naturales, la conquista 
y colonización a finales del siglo xv tuvo como objetivo fundamental extraer por la fuerza los recursos agrícolas y mineros que allí existían. Y en efecto, fueron enormes cantidades de alimentos, oro y plata que casi gratuitamente se trasladaron hacia los países occidentales, hoy en día convertidos en grandes potencias económicas mundiales. En aquella época, el costo que los extranjeros pagaban por la extracción de esos recursos era, paradójicamente, la pérdida de culturas, costumbres, religiones, lenguas y vidas humanas indígenas; mientras que el beneficio que quedaba para el progreso de los pueblos autóctonos era prácticamente insignificante.

Por inicios del siglo XIX, en pleno auge del capitalismo, los pueblos colonizados adquirieron su independencia y expandieron las actividades de extracción de recursos naturales para fortalecer sus incipientes y débiles economías y, principalmente, para sostener varias revoluciones tecnológicas que se suscitarían posteriormente en el exterior. Pero, a diferencia de la época de la conquista, esta vez los ingresos generados ya no salían en su totalidad hacia el extranjero gratuitamente; sino que, en gran parte quedaban dentro del territorio nacional y eran utilizados por los nuevos gobiernos republicanos para pagar el costo de la independencia y financiar el progreso de la población. Desde entonces, y más formalmente con el «Consenso de Washington» — segunda mitad del siglo $\mathrm{xx}$-, el mundo entero emprende a toda velocidad una carrera productivista-consumista desenfrenada en busca del desarrollo de la sociedad.

Con la globalización instaurada a finales del siglo xx, se hizo imprescindible una mayor demanda de recursos naturales, especialmente por parte de los países industrializados. Aquello ha provocado que hoy en día los países pobres, lejos de abandonar sus prácticas extractivistas, las profundicen aún más con el apoyo de una nueva clase política populista y poco honesta. El mejor ejemplo de esto lo constituyen varios países de Sudamérica, pues algunos gobernantes progresistas que se declaran abiertamente antineoliberales, con el pretexto de construir más hospitales y escuelas, contradictoriamente, en sus discursos - y en algunos casos violando la Constitución -, prometen salir del extractivismo con más extractivismo - megaminería a cielo abierto, biocombustibles, etcétera-, sin importarles la pérdida de biodiversidad, culturas e identidades; la escasez de alimentos; los desplazamientos humanos forzosos y la contaminación que esto genera, especialmente en las poblaciones locales, que normalmente son comunidades indígenas.

Desde su punto de vista, Svampa (2013) sostiene que actualmente América Latina, por buscar un mayor desarrollo, ha pasado del «Consenso de Washington» al «Consenso de los commodities», es decir, ha dejado a un lado las políticas económicas de liberalización, desregulación y privatización indiscriminada, y ha adoptado tácitamente un nuevo ordenamiento socioeconómico caracterizado por la extracción y exportación de recursos naturales a gran escala, el mismo que tiene como contrapartida la reprimarización de la economía, reconcentración de la riqueza, desposesión de tierras, dependencia de otros países, conflictividad territorial y merma de todo tipo de derechos.

En definitiva, se ha pasado a vivir un neoextractivismo (neodesarrollismo progresista) que no difiere mucho del extractivismo viejo, pues el objetivo final es el mismo: sostener el sistema capitalista de las grandes metrópolis y financiar el incipiente desarrollo de los países pobres, pero ahora con extracciones de mayores cantidades de recursos naturales, en nuevos territorios y en áreas protegidas, como es el caso del petróleo del Parque Nacional Yasuní en el 
Tabla 1. Reservas probadas de petróleo crudo por países

\begin{tabular}{lllll}
\hline País & $\begin{array}{l}\text { Reservas probadas de } \\
\text { petróleo, al año 2017 } \\
\text { (millones de barriles) }\end{array}$ & $\begin{array}{l}\text { Valor de las reservas probadas } \\
\text { de petróleo, al año 2017 } \\
\text { (millones de USD) }\end{array}$ & $\begin{array}{l}\text { Producción promedio de } \\
\text { petróleo en el año 2017 } \\
\text { (miles de barriles por día) }\end{array}$ & $\begin{array}{l}\text { Fecha de agotamiento } \\
\text { de las reservas probadas } \\
\text { de pretróleo (año) }\end{array}$ \\
\hline Bolivia & 44 & 2.310 & 10 & 2029 \\
\hline Perú & 435 & 22.842 & 44 & 2044 \\
\hline Colombia & 1.665 & 87.429 & 854 & 2022 \\
\hline Ecuador & 1.704 & 89.477 & 514 & 2026 \\
\hline Argentina & 2.162 & 113.527 & 483 & 2029 \\
\hline Brasil & 12.634 & 663.411 & 2.150 & 2033 \\
\hline Venezuela & 302.809 & $15 ’ 900.501$ & 2.035 & 2424 \\
\hline
\end{tabular}

Nota: El valor de las reservas probadas de petróleo se calculó multiplicando la cantidad por el precio promedio del petróleo fijado por la Organización de Países Exportadores de Petróleo (OPEP) en el año 2017, el cual fue de USD 52,51 por barril. La fecha de agotamiento de las reservas probadas de petróleo puede aumentar en el caso de que se descubran en el futuro nuevos yacimientos de hidrocarburos. Fuente: OPEP (2018), Statista (2018). Elaboración: propia.

Ecuador o el caso de los minerales del Parque Nacional Isoboro Sécure en Bolivia, entre otros (Gudynas, 2012, págs. 33-38).

A pesar de que últimamente en los países extractivistas, como Ecuador y otros de Sudamérica, se han realizado importantes reformas legales para un mejor control y aprovechamiento de los recursos naturales que explotan, éstas no han sido de fondo, pues dichos recursos siguen siendo extraídos intensivamente y, controlados y manejados por las grandes potencias mundiales; un ejemplo de aquello lo constituye el Estado ecuatoriano, donde China adquiere y comercializa más de la mitad de su petróleo, manteniéndose de esta manera la eterna dependencia de los países ricos a través de la deuda externa (Schneyer y Mora, 2013).

En este contexto, con el actual ritmo de sobreconsumo de bienes manufacturados - y, por ende, de recursos naturales- que lleva el mundo entero, tal parece que el extractivismo no se detendrá por voluntad del ser humano; pero sí hay evidencias empíricas de que en poco tiempo desaparecerá por cuenta propia. Por ejemplo, ya existen estudios científicos que demuestran que en la segunda mitad del siglo xxi habrá una súbita disminución de la disponibilidad de recursos naturales del planeta (Meadows, citado en Gudynas, 2012, pág. 25); específicamente hablando, en el caso de Ecuador se estima que las reservas probadas de petróleo crudo $^{4}$ se terminarán muy pronto, después de 8 años (aproximadamente en el año 2026), si se las continúa extrayendo bajo las condiciones actuales (Secretaría de Hidrocarburos, 2018, pág. 10, 16), situación parecida que la viven también los otros países de la región a excepción de Venezuela (ver Tabla 1). Asimismo, se calcula que a mediados del siglo xxi los recursos pesqueros de todos los mares se agotarán si se los sigue capturando a tasas tan elevadas como las que se practican en estos momentos (Worm, et al., 2006, pág. 790).

\section{LOS INGRESOS FINANCIEROS DE LAS ACTIVIDADES EXTRACTIVAS EN EL ECUADOR}

Si bien es cierto que en el Ecuador las actividades económicas extractivistas, empezaron a realizarse con intensidad desde la conquista de los españoles, el registro formal de las mismas apenas comenzó en la década de 1840 aproximadamente con la producción de cacao ${ }^{5}$ (Roberts, 
2010, pág. 35) y, posteriormente, con las producciones de banano en la década de 1940 (Acosta, 2012a, págs. 122, 482) y de petróleo en la década de 1970 (Llanes, 2008, pág. 214). Aunque solo una parte de esta producción era vendida en el mercado local, el mayor de los ingresos monetarios provenía de las exportaciones que se hacían - y se siguen haciendo- a varios países de otros continentes.

La producción de recursos naturales renovables tales como el cacao, banano, camarón, etcétera, desde el inicio ha sido realizada únicamente por las empresas privadas; de modo que el Estado ha participado parcialmente de los ingresos provenientes de estas actividades, únicamente a través del cobro de impuestos. No obstante, lo contrario sucede con la extracción de recursos naturales no renovables como el petróleo o los minerales, pues el Estado al ser el dueño absoluto de estos recursos, recibe el cien por ciento de los ingresos generados. ${ }^{6}$

Solo por tener una idea general de la magnitud, a continuación se muestra en valores presentes de 2014 la totalidad de los ingresos que el Ecuador ha obtenido de la exportación de su petróleo durante el periodo comprendido entre los años 1972 y 2013 (ver Tabla 2). En este artículo se elige únicamente a este recurso natural para el análisis, porque es más fácil obtener la información, es el que mayor impacto tiene en el PIB de entre todos los recursos naturales $\mathrm{y}$, sobre todo, en los últimos años su extracción es la que mayor controversia ha generado en la sociedad desde el punto de vista económico, político y ambiental.

Los ingresos históricos que el Ecuador ha depositado en sus arcas fiscales por concepto de la exportación de petróleo, son altos, pero aún más altos son los ingresos que han obtenido los otros países de la región (ver Tabla 3), sobresaliendo principalmente Brasil y Venezuela.

\section{¿POR QUÉ EL EXTRACTIVISMO NO DESARROLLA A LA POBLACIÓN?}

A lo largo de toda la historia, el extractivismo ha sido practicado por todas partes del mundo, y últimamente con mayor intensidad en Sudamérica, pues allí se encuentra una riqueza muy amplia y variada de materias primas que necesita el primer mundo para mantener en marcha su maquinaria industrial. Pero, a pesar de las grandes cantidades de recursos monetarios que ha generado en todo este tiempo el extractivismo, ninguno de los países que ha anclado su aparato productivo a esta actividad económica primaria ha logrado desarrollarse; por el contrario, son los países que mantienen los índices de inequidad, miseria y deterioro ambiental más elevados del planeta.

Por citar un ejemplo de aquello, se puede revelar con un alto grado de confianza que Latinoamérica, el primer exportador de recursos naturales del planeta, ya pasó a ser el territorio de mayor desigualdad económica del mundo, encontrándose cifras alarmantes que muestran que el 10\% más rico de la población se apropia del 71\% de la riqueza material que se genera en la región (Comisión Económica para América Latina y el Caribe, CEPAL, 2016). En términos más concretos, en Brasil el 1\% más rico de la población se apropia del 28\% del ingreso; asimismo, en Colombia el 1\% más rico se apropia del 21\% del ingreso, en Ecuador el 1\% se apropia del $16 \%$ del ingreso, mientras que en China sucede lo contrario, pues el $1 \%$ más rico se apropia tan solo del 6\% del ingreso (CEPAL, 2018, pág. 87). La desigualdad en América Latina y el Caribe no solo se manifiesta en los ingresos, sino también en «[...] activos físicos y financieros, 
Tabla 2. Ingresos de las exportaciones del petróleo crudo ecuatoriano

\begin{tabular}{|c|c|c|}
\hline \multirow[b]{2}{*}{ Año } & \multicolumn{2}{|c|}{ Empresas del Estado } \\
\hline & Valor FOB & Valor al año 2014 \\
\hline & (millones de USD) & (millones USD) \\
\hline 1972 & 62,4 & 171,7 \\
\hline 1973 & 298,7 & 802 \\
\hline 1974 & 772,1 & $2.022,60$ \\
\hline 1975 & 601,1 & $1.536,20$ \\
\hline 1976 & 648,6 & $1.617,20$ \\
\hline 1977 & 655,9 & $1.595,50$ \\
\hline 1978 & 556,1 & $1.319,70$ \\
\hline 1979 & 953,3 & $2.207,20$ \\
\hline 1980 & $1.361,10$ & $3.074,50$ \\
\hline 1981 & $1.553,80$ & $3.424,20$ \\
\hline 1982 & $1.156,30$ & $2.486,10$ \\
\hline 1983 & $1.514,50$ & $3.176,80$ \\
\hline 1984 & $1.607,40$ & $3.289,40$ \\
\hline 1985 & $1.673,20$ & $3.340,50$ \\
\hline 1986 & 855,7 & $1.666,70$ \\
\hline 1987 & 644,8 & $1.225,30$ \\
\hline 1988 & 679 & $1.258,80$ \\
\hline 1989 & 963,6 & $1.742,90$ \\
\hline 1990 & $1.190,60$ & $2.100,90$ \\
\hline 1991 & $1.046,60$ & $1.801,80$ \\
\hline 1992 & $1.236,00$ & $2.076,00$ \\
\hline 1993 & $1.140,00$ & $1.868,00$ \\
\hline 1994 & $1.178,90$ & $1.884,60$ \\
\hline 1995 & $1.355,30$ & $2.113,80$ \\
\hline 1996 & $1.456,20$ & $2.215,80$ \\
\hline 1997 & $1.190,90$ & $1.767,90$ \\
\hline 1998 & 631,3 & 914,3 \\
\hline 1999 & 855 & $1.208,10$ \\
\hline 2000 & $1.073,80$ & $1.480,20$ \\
\hline 2001 & 899,9 & $1.210,30$ \\
\hline 2002 & 964,8 & $1.265,90$ \\
\hline 2003 & $1.130,00$ & $1.446,50$ \\
\hline 2004 & $1.622,00$ & $2.025,70$ \\
\hline 2005 & $2.300,10$ & $2.802,40$ \\
\hline 2006 & $3.730,40$ & $4.434,30$ \\
\hline 2007 & $4.011,90$ & $4.652,60$ \\
\hline 2008 & $6.460,70$ & $7.309,70$ \\
\hline 2009 & $4.459,70$ & $4.922,70$ \\
\hline 2010 & $6.728,60$ & $7.246,00$ \\
\hline 2011 & $10.314,80$ & $10.837,00$ \\
\hline 2012 & $11.063,90$ & $11.340,50$ \\
\hline 2013 & $11.900,90$ & $11.900,90$ \\
\hline TOTAL & & $126.783,20$ \\
\hline
\end{tabular}

\begin{tabular}{cc}
\hline \multicolumn{2}{c}{ Empresas privadas } \\
\hline Valor FOB & Valor al año 2014 \\
\hline (millones USD) & (millones de USD)
\end{tabular}

Nota: FOB son las siglas en inglés de «libre a bordo», significa que la mercancía es puesta a bordo del buque. Los valores de las exportaciones de cada año son llevados a valor presente utilizando la tasa de interés de 2,5\% anual, la cual corresponde al promedio de las tasas de interés que Estados Unidos pagó en el periodo 200o-2013 a los depósitos de un año de plazo. Fuente: Banco Central del Ecuador (2014), Federal Reserve System (2014). Elaboración: propia.

capacidades, oportunidades, productividad, habitabilidad, poder, acceso al bienestar, redes de relaciones y goce de derechos»; y a la larga resulta ineficiente porque obstaculiza el crecimiento, el desarrollo y la sostenibilidad en todos los ámbitos de la vida (CEPAL, 2018, pág. 15).

Como se indicó en la sección anterior, en el caso ecuatoriano los ingresos históricos 
obtenidos de la exportación de petróleo solo de las empresas del Estado ascienden aproximadamente a USD 126.783,2 millones en valores actuales de 2014 (ver Tabla 2), cifra muy importante y suficiente como para financiar un aumento sustancial de la calidad de vida de todos nuestros compatriotas. Sin embargo, se ve que en la realidad esto no ha sucedido, pues desafortunadamente tenemos que hasta junio del 2018 a nivel nacional el $24,5 \%$ de los ecuatorianos seguía siendo pobre por ingresos, y el 9\%, extremadamente pobres; el coeficiente de Gini se mantiene en el valor de 0,472 , lo cual refleja todavía una desigualdad alta con respecto a la distribución del ingreso per cápita (Instituto Nacional de Estadística y Censos, INEC, 2018a, págs. 6,15$)$. De igual manera, las tasas de desempleo y subempleo nacional son elevadas, de 4,1\% y 19,4\% respectivamente (INEC, 2018b, págs. 4, 6).

El resto de países sudamericanos presenta también índices de desigualdad altos, por ejemplo, Venezuela tiene un coeficiente de Gini de o,40, Perú de 0,45, Argentina de 0,47, Bolivia de 0,48, Colombia de 0,52, Brasil de 0,57, siendo el promedio de la región 0,50; valores muy elevados si consideramos que Suecia tiene un valor de 0,19 y Europa Oriental y Asia Central tienen un valor promedio de 0,32 (CEPAL, 2018, págs. 88, 129, 175).

Con respecto al tema ambiental, se evidencia de igual manera que los países extractivistas están expuestos a un constante daño ecológico a causa de esta actividad. En el Ecuador, por ejemplo, durante la segunda mitad del siglo xx alrededor de dos millones de hectáreas de selva amazónica fueron contaminadas con residuos tóxicos por la compañía petrolera Texaco (Ministerio de Relaciones Exteriores y Movilidad Humana, 2018, pág. 2). De igual forma, desde el punto de vista cultural, la explotación de los recursos naturales, especialmente los de origen hidrocarburífero, ha provocado en las nacionalidades indígenas ecuatorianas su desplazamiento forzoso, la reducción de su espacio territorial y la pérdida de sus valores y costumbres ancestrales; además, en el ámbito social ha permitido la presencia del alcoholismo y la prostitución (Agencia Alemana de Cooperación Técnica, 2011, pág. 5).

Por lo tanto, en esta instancia del análisis, resulta imprescindible preguntarse ¿por qué el extractivismo contribuye muy poco al mejoramiento del bienestar de los pueblos a pesar de generar grandes cantidades de ingresos financieros? Con el fin de responder ampliamente a esta interrogante, a continuación se establecen algunas de las que se cree son las causas principales para que el extractivismo no se haya convertido en un factor contundente de desarrollo socioeconómico en los países donde se lo realiza, especialmente en el Ecuador:

- Los países que disponen de una gran cantidad de recursos naturales, esperanzados de los ingresos «fáciles» que obtienen por la venta de dichos recursos, adoptan una cultura rentista ${ }^{7}$ y poco o nada hacen para desarrollar la industria, la ciencia y la tecnología, tres elementos básicos que realmente contribuyen a agregar valor en la economía para su crecimiento (Acosta, 2012b, pág. 87). Un ejemplo de aquello lo constituye el caso ecuatoriano, país con abundantes recursos naturales, pero que durante décadas mantiene un bajo grado de industrialización, ${ }^{8}$ de 11,8\% en el año 2014 (Ekos, 2015), en comparación con el 26,6\% del promedio mundial (Banco Mundial, 2018).

- Los países ricos en recursos naturales, al no poder potenciar su industria, se convierten solo en exportadores de materias primas, y no se desarrollan porque son los que pagan el costo del «deterioro de los términos de intercambio» ${ }^{9}$ generado en las transacciones comerciales. Así, 
Tabla 3. Ingresos por producción de petróleo crudo (por países)

\begin{tabular}{|c|c|c|c|c|c|}
\hline \multirow[t]{2}{*}{ Año } & \multicolumn{4}{|c|}{ Valor de los ingresos (millones de USD) } & \multirow[b]{2}{*}{ Venezuela } \\
\hline & Perú & Argentina & Colombia & Brasil & \\
\hline 1970 & 28,3 & 169,8 & 96,3 & 72,6 & $1.637,60$ \\
\hline 1972 & 42,6 & 289,2 & 129,1 & 110,9 & $2.139,00$ \\
\hline 1973 & 68,8 & 413,6 & 180,6 & 167,7 & $3.317,20$ \\
\hline 1974 & 301,1 & $1.669,00$ & 668,9 & 712,4 & $11.949,80$ \\
\hline 1976 & 317,6 & $1.643,60$ & 613,2 & 705,9 & $9.714,50$ \\
\hline 1977 & 403,3 & $1.990,10$ & 622,3 & 733,7 & $10.210,40$ \\
\hline 1978 & 730,8 & $2.104,00$ & 605,2 & 748,4 & $10.109,40$ \\
\hline 1979 & $2.035,50$ & $5.025,30$ & $1.313,80$ & $1.764,30$ & $25.106,00$ \\
\hline 1980 & $2.482,20$ & $6.373,40$ & $1.615,40$ & $2.353,70$ & $28.068,80$ \\
\hline 1985 & $1.871,40$ & $4.537,80$ & $1.739,40$ & $5.394,90$ & $15.418,90$ \\
\hline 1986 & 876,8 & $2.145,60$ & $1.491,20$ & $2.829,30$ & $8.141,00$ \\
\hline 1987 & $1.060,30$ & $2.776,20$ & $2.491,80$ & $3.666,20$ & $10.195,80$ \\
\hline 1988 & 737 & $2.314,50$ & $1.948,00$ & $2.883,60$ & $8.202,50$ \\
\hline 1989 & 823,9 & $2.900,80$ & $2.554,20$ & $3.766,00$ & $11.040,30$ \\
\hline 1990 & $1.047,20$ & $3.928,70$ & $3.571,30$ & $5.129,10$ & $17.348,30$ \\
\hline 1991 & 780,2 & $3.330,80$ & $2.893,00$ & $4.238,10$ & $15.537,70$ \\
\hline 1992 & 777,8 & $3.729,80$ & $2.950,40$ & $4.227,00$ & $15.787,30$ \\
\hline 1993 & 752,6 & $3.538,80$ & $2.701,00$ & $3.834,30$ & $13.864,00$ \\
\hline 1994 & 721,6 & $3.784,80$ & $2.573,70$ & $3.786,60$ & $13.422,30$ \\
\hline 1995 & 749,3 & $4.426,30$ & $3.599,30$ & $4.264,80$ & $14.637,10$ \\
\hline 2002 & 861,3 & $6.733,00$ & $5.140,40$ & $12.931,60$ & $24.735,90$ \\
\hline 2003 & 936,9 & $7.589,90$ & $5.550,00$ & $15.344,80$ & $27.107,90$ \\
\hline 2004 & $1.238,50$ & $9.140,90$ & $6.990,80$ & $19.439,60$ & $39.598,40$ \\
\hline 2005 & $2.055,10$ & $12.271,50$ & $9.708,50$ & $30.164,50$ & $56.629,50$ \\
\hline 2006 & $1.727,40$ & $14.643,10$ & $11.823,80$ & $38.356,70$ & $67.587,60$ \\
\hline 2007 & $1.941,40$ & $16.165,20$ & $13.344,30$ & $44.048,50$ & $75.143,30$ \\
\hline 2008 & $2.630,00$ & $22.036,40$ & $20.199,90$ & $62.239,30$ & $101.581,00$ \\
\hline 2009 & $1.593,90$ & $13.408,60$ & $14.895,00$ & $43.326,20$ & $63.932,90$ \\
\hline 2010 & $2.051,70$ & $16.640,10$ & $22.183,80$ & $58.033,20$ & $80.597,30$ \\
\hline 2011 & $2.729,40$ & $21.705,20$ & $35.895,00$ & $82.578,70$ & $112.997,50$ \\
\hline 2012 & $2.659,50$ & $21.943,30$ & $37.720,80$ & $82.348,30$ & $112.014,90$ \\
\hline 2013 & $2.427,40$ & $20.865,60$ & $38.958,60$ & $78.207,10$ & $107.792,90$ \\
\hline 2014 & $2.436,40$ & $18.705,40$ & $34.806,30$ & $79.239,30$ & $94.283,40$ \\
\hline 2015 & $1.048,80$ & $9.618,80$ & $18.172,30$ & $44.044,70$ & $47.958,50$ \\
\hline 2016 & 598,8 & $7.612,40$ & $13.140,50$ & $37.341,60$ & $35.296,70$ \\
\hline 2017 & 834,2 & $9.263,40$ & $16.359,80$ & $50.249,80$ & $38.999,30$ \\
\hline $\mathrm{T}$ & 57.826 & 344.099 & 376.318 & 890.286 & 1'547.064 \\
\hline
\end{tabular}

Nota: Los ingresos se obtuvieron multiplicando la cantidad de petróleo producido por el precio promedio de cada año fijado por la OPEP. El monto de los ingresos reportados en cada año no ha sido llevado a valor presente. Fuente: OPEP (2018), Statista (2018). 
cuando los precios internacionales de las materias primas disminuyen - hecho que ocurre con mucha frecuencia porque son más volátiles que los precios de las manufacturas- sus balanzas de pago entran en déficit y, para equilibrarlas, nuevamente tienen que endeudarse, lo cual a su vez les obliga a aumentar la extracción de sus recursos naturales para poder honrar el servicio de la deuda; esto, a la larga, se convierte en un círculo vicioso de mayor endeudamiento/mayor extracción, que se repite constantemente obstaculizando el desarrollo. En el caso de Ecuador esta situación es muy evidente, pues su deuda externa pública pasó de usD 12.351 millones en 1996 a USD 31.577 millones en el 2018 (Banco Central del Ecuador, 2018a).

- Los países que son propietarios de bastantes recursos naturales, al no poder desarrollar su industria, envían al exterior grandes cantidades de dinero para adquirir los bienes manufacturados que no producen. De esta manera, generan una balanza comercial deficitaria que los obliga a endeudarse y suprimir recursos previstos para el progreso de los pueblos. Por citar un ejemplo, se puede indicar que en el año 2017 el Ecuador envió al extranjero USD 19.298 millones por concepto de importaciones, con una contrapartida por exportaciones de USD 19.621 millones (Banco Central del Ecuador, 2018b).

- Los gobiernos extractivistas no destinan los ingresos obtenidos de la extracción y venta de sus recursos naturales a verdaderos proyectos de reducción de la desigualdad y la pobreza (Cisneros, 2011, pág. 115); sino que los utilizan para otros fines poco desarrolladores, tales como el pago de subsidios a los combustibles, que para el caso ecuatoriano ascendieron a USD 1900 millones en el 2017 (Pacheco, 2018); la condonación de deudas; el pago de la excesiva propaganda pública; la concesión de privilegios a la élite empresarial, entre los cuales destacan la reducción de impuestos, la sucretización de la deuda privada y el salvataje bancario, teniendo este último un costo de USD 6170 millones en 1999 para el caso ecuatoriano (El Telégrafo, 2014); la cancelación de los sueldos del exceso de funcionarios públicos provenientes de las cuotas políticas, el pago del consumismo suntuario de bienes importados, el pago de favores políticos, la corrupción, entre otros.

- Los países extractivistas envían una gran parte de sus rentas al extranjero a través de las empresas transnacionales (por concepto de dividendos), pues obligatoriamente tienen que negociar con estas organizaciones porque necesitan de su ayuda para poder reforzar su incipiente tecnología y financiar las altas inversiones que demandan las actividades extractivas. De esta manera, solo una pequeña parte de la renta proveniente de la extracción de los recursos naturales se queda dentro del territorio nacional, la cual resulta ser insuficiente para costear los diversos programas de desarrollo social emprendidos por los distintos gobiernos. Al respecto, se puede citar un ejemplo en el sector hidrocarburífero ecuatoriano, donde existían contratos que establecían que el $20 \%$ del petróleo crudo extraído era para el Estado y el 80\% para la empresa petrolera (Correa, 2015, pág. 18).

- El extractivismo utiliza tecnología intensiva en capital (generalmente traída del extranjero) y, por lo tanto, genera poco empleo en general. Además, la posesión de recursos naturales en abundancia tiende a «[...] distorsionar la estructura económica y la asignación de los factores productivos; redistribuye regresivamente el ingreso y concentra la riqueza en pocas 
manos [...], crea aparatos productivos con estructuras heterogéneas y concentra la exportación en unos pocos productos primarios» (Acosta, 2012b, págs. 88, 90). Todo esto hace que los países que se dedican a esta actividad no puedan generar encadenamientos productivos y una suficiente demanda efectiva capaz de desarrollar la industria local y, por ende, crear valor agregado. Situaciones como estas se pueden encontrar en Venezuela y Ecuador, quienes actualmente mantienen concentradas sus exportaciones en los hidrocarburos, por lo que al menor descenso de los precios internacionales del petróleo, sus balanzas comerciales entran en crisis, debilitando así su estructura económica y la asignación de recursos financieros en la sociedad.

- Los Estados dueños de recursos naturales (especialmente petróleo y minerales) no se desarrollan porque continuamente sufren la pérdida irreversible de su patrimonio natural, el deterioro de sus ecosistemas por el uso de químicos tóxicos y, sobre todo, están expuestos a una alta contaminación que causa en los individuos muchas enfermedades, las mismas que una vez generadas, demandan por parte de las autoridades gubernamentales una mayor asignación de recursos monetarios en el sistema de salud pública para poder curarlas. Como ya se mencionó antes, una muestra de aquello lo constituye la empresa petrolera Texaco, la que contaminó la Amazonía ecuatoriana destruyendo ecosistemas naturales y causando enfermedades terminales a los habitantes de las comunidades indígenas nativas.

- Las naciones que extraen importantes cantidades de recursos naturales no progresan porque los distintos grupos sociales internamente libran grandes «guerras civiles», ya sea por salvaguardar la naturaleza o por la disputa de la renta generada. Además, debilitan su democracia y tienden a quedarse con regímenes autoritarios, debido a que los gobiernos extractivistas en defensa de sus políticas fiscales expansivas, reprimen con la fuerza militar las protestas que realizan las personas en rechazo a las actividades de extracción contaminadoras impuestas en sus territorios, coartando de esta forma el desarrollo de las libertades y los derechos de los ciudadanos. En el Ecuador, un caso emblemático de este tipo de violencia social lo constituye el pueblo indígena Sarayaku de la Amazonía, el que en el 2003 fue reprimido por la fuerza militar por oponerse a que se extraiga hidrocarburos en sus territorios, conflicto que más tarde fue llevado a la Corte Interamericana de Derechos Humanos para que medie la situación (Fundación Regional de Asesoría en Derechos Humanos, INREDH, 2016). - Los países extractivistas no se desarrollan porque quedan sometidos a las decisiones que toman los países que compran sus materias primas, que, por lo general, son las grandes potencias mundiales. Es decir, cuando los gobiernos extractivistas no están alineados a la ideología política de los países ricos que demandan sus recursos naturales, quedan expuestos a severos bloqueos económicos que retrasan e impiden el progreso de los pueblos, como es el caso de Cuba y Venezuela, las que actualmente sufren la discriminación de Estados Unidos por no pensar igual.

Frente al limitado impacto positivo, que genera el extractivismo en el progreso y bienestar integral de la sociedad y, fundamentalmente, por el perjuicio irreversible que esta actividad causa al medioambiente, sobre todo cuando ocurren accidentes de contaminación, hace poco han emergido nuevos planteamientos paradigmáticos y revolucionarios como alternativas sostenibles de desarrollo, principalmente para aquellos países capitalistas como el Ecuador que 
durante décadas han estructurado sus economías en función de la extracción de todo tipo de recursos naturales y que, al final de cuentas, nunca han alcanzado el tan anhelado desarrollo.

En este sentido, aparece la tesis del Desarrollo Sustentable, la misma que busca satisfacer las necesidades de la población actual, pero sin reducir la capacidad de las futuras generaciones para satisfacer sus propias necesidades (Ramírez, Sánchez y García, 2004, pág. 55). También surge la tesis del Buen Vivir, la cual propone aumentar la calidad de vida de todas las personas, pero sin transgredir los derechos que tienen los ecosistemas naturales para autoregenerarse (Constitución de la República del Ecuador, 2008); o la tesis del Crecimiento Verde, la misma que plantea lograr un crecimiento industrial basado en una producción más limpia y el manejo eficiente de los recursos y la energía (Ministerio de Industrias y Productividad, 2012). Finalmente, entre otras, está la tesis del Decrecimiento Económico, la cual recomienda dejar de crecer desproporcionadamente como se está haciendo ahora, para empezar a decrecer sostenidamente a una tasa óptima, tal que nos permita alcanzar un mundo más equilibrado económica y ambientalmente basado en una distribución y redistribución más equitativa de la renta social (Latouche, 2009, págs. 15, 45).

Todos estos planteamientos teóricos que tienen como objetivo proteger y preservar los bienes y servicios naturales que ofrece el planeta, se vienen debatiendo desde hace algunos años atrás; sin embargo, ningún gobierno los ha aplicado en su totalidad porque, por un lado, a los países pobres les urge la necesidad de seguir explotando la naturaleza para financiar sus débiles economías y, por el otro, están los países ricos que les urge la necesidad de obtener cada día más materias primas para abastecer a sus enormes complejos industriales, sin importarles mucho lo que suceda con el futuro del medio natural. De esta manera, la Tierra es vista por la humanidad únicamente como un factor productivo más, que está solo para resolver los problemas económicos que se le presentan a la sociedad.

\section{A MANERA DE CONCLUSIONES}

Paradójicamente, los países que poseen grandes riquezas en recursos naturales (materias primas) son los más precarios y subdesarrollados del mundo; un ejemplo visible de aquello, se puede apreciar actualmente en Venezuela, nación con las mayores reservas de petróleo del planeta (Cigüenza, 2018), pero con severos problemas de escasez de alimentos, elevadas tasas de pobreza e inflación, crisis democráticas y una masiva emigración internacional de la población en busca de mejores empleos en los países vecinos. Aquello se debe principalmente a que los gobernantes malgastan los ingresos provenientes de las exportaciones de dichos recursos naturales y, sobre todo, con sus políticas paternalistas generan una mentalidad clientelar en los empresarios y en la ciudadanía en general, que los lleva a no esforzarse y aportar muy poco con ideas innovadoras dirigidas a fortalecer la industria, uno de los factores clave para impulsar y sostener el desarrollo y bienestar de la gente.

Para revertir esta situación negativa, y así lograr un mayor crecimiento económico que repercuta favorablemente en el bienestar integral de la sociedad, los países extractivistas deben asignar más eficientemente los recursos monetarios obtenidos a partir de esta actividad. En este sentido, la CEPAL (2018, pág. 13) recomienda a los países de la región destinar sus ingresos 
a la inversión, diversificación productiva, incorporación de tecnologías, reducción de brechas sociales y disminución de costos ambientales.

Según las investigaciones científicas realizadas, los recursos naturales del planeta experimentarán una reducción súbita en el corto plazo, por lo que, si no se encuentra ahora nuevas y mejores alternativas de desarrollo independientes del extractivismo a gran escala, la población mundial tendrá graves dificultades para satisfacer sus necesidades básicas, aumentando el riesgo de que se presenten muertes masivas de personas por falta de subsistencias.

En términos generales, el modelo extractivista, a la larga, no se convierte en un motor de desarrollo de un país porque crea una cultura rentista en la población, lo vuelve únicamente en exportador de materias primas, envía grandes sumas de dinero al exterior por concepto de importaciones, no destina los ingresos a proyectos de reducción de la pobreza, envía gran parte de su renta al extranjero con concepto de dividendos, usa tecnología intensiva en capital que genera poco empleo, sufre la pérdida irreversible de su patrimonio natural, los grupos sociales internamente libran grandes guerras civiles y, hace que las economías subdesarrolladas se vuelvan dependientes de las economías de los países desarrollados, pues son estos últimos los que a través de su consumo determinan los precios y la cantidad de materias primas que deben extraer y producir los países pobres. De esta manera, los ingresos y el desarrollo de los países extractivistas se vuelve una especie de limosna que está supeditada a la voluntad de los países industrializados.

Las actividades extractivas generan grandes problemas socioeconómicos y socioambientales dentro de una nación, los cuales constituyen externalidades negativas que retrasan el progreso de los pueblos. Dichas externalidades tienen que ver principalmente con la concentración de la riqueza, contaminación ambiental y discriminación, irrespeto y subvaloración de las culturas, religiones, libertades y voluntades de las personas y nacionalidades indígenas que habitan en los lugares de influencia.

En la primera década del siglo xxI apareció una nueva forma de extractivismo basado en la explotación a gran escala de los recursos naturales, impulsada por muchos gobiernos progresistas, especialmente de Sudamérica. Este neoextractivismo, que solo cambia de matices y discurso, en el fondo tiene el mismo objetivo que el extractivismo clásico: exportar materias primas para mejorar el bienestar de los países desarrollados a cambio del deterioro del bienestar de los países subdesarrollados.

Salir del extractivismo en los países pobres, para pasar a una etapa postextractivista de mayor bienestar sí es posible. Para conseguir aquello, primero tenemos que descolonizar nuestra forma de pensar y adoptar un estilo de vida propio, que tenga como eje central los más elementales principios de convivencia comunitaria y de solidaridad e impulse el desarrollo de la ciencia y la tecnología solo hasta escalas necesarias. Se debe dejar de depender de las economías de los países industrializados y desarrollar nuestro mercado interno, producir localmente los bienes que se necesita, distribuir más equitativamente la riqueza y cambiar nuestros desenfrenados hábitos de consumo excesivo por otros que respeten, por un lado, el derecho que tienen las demás personas a satisfacer sus propias necesidades y, por el otro, el derecho que tiene la misma naturaleza a regenerarse y conservarse. Se necesita el compromiso pleno de todos los gobernantes y de la ciudadanía en general, los cuales deben hacer conciencia de que 
si continuamos sobreexplotando los escasos recursos que nos brinda la generosa naturaleza, pronto el planeta alcanzará sus límites permisibles y toda forma de vida sobre él lamentablemente desaparecerá o, en el mejor de los casos, será posible solo para unos pocos privilegiados.

Por lo tanto, el desafío de la sociedad moderna está en cómo disminuir la dependencia arraigada que tienen los ingresos públicos de los ingresos provenientes de los recursos naturales no renovables. Sin lugar a dudas, se tendría que abandonar este sector primario para empezar a operar dentro de sectores más rentables, como lo son los sectores de la industria y los servicios. En este sentido, la política fiscal desempeña un papel importante en la redistribución del ingreso, por un lado orientando el gasto público cada vez, en mayor proporción, a los principales sectores sociales tales como salud, educación, vivienda y bienestar social, así como también a aquellos sectores que potencian el desarrollo como son los de infraestructura, que integran al territorio y dotan de servicios para la producción y para mejorar la calidad de vida de la población.

En concordancia con lo anterior, resulta imprescindible ampliar los recursos públicos, para lo cual se requiere aumentar los ingresos tributarios, especialmente el impuesto a la renta de manera progresiva, exigiendo mayores esfuerzos contributivos de quienes tienen mayores recursos económicos; redefinir las reglas impositivas de las industrias extractivas y de los consumos especiales, todo esto habida cuenta de que el Ecuador se encuentra dentro de los países que tienen una menor participación de los ingresos tributarios como porcentaje del PIB. Especial atención se debe prestar a los subsidios de los combustibles, una alternativa viable podría ser controlar dicho subsidio a través del consumo; es decir, mantener los subsidios hasta un límite -30 o 40 galones por mes por vehículo en el caso de la gasolina- y sobre ese límite cobrar el precio internacional.

\section{NOTAS}

1 El extractivismo se refiere a la extracción de los recursos naturales, tanto renovables (madera, peces, banano, cacao, etcétera) como no renovables (petróleo, minerales, etcétera), que ofrece el planeta Tierra. Se caracteriza, porque los productos extraídos son destinados principalmente a la exportación con nada o muy poco valor agregado; es decir, sin ser procesados (Acosta, 2012b, pág. 85). El extractivismo es una forma de acumulación de capital que realizan los países subdesarrollados basada en la especialización primaria-exportadora del trabajo, la cual es totalmente contraria a la especialización de industrialización que realizan los países desarrollados.

2 La visión antropocéntrica considera que el ser humano está sobre todas las cosas.

3 La visión biocéntrica considera que se debe respetar toda forma de vida.

4 Las «reservas probadas» de petróleo son los volúmenes de petróleo que sí tienen una certeza razonable de ser recuperados comercialmente con la tecnología vigente, cosa que no sucede con los otros tipos de reservas, como las reservas probables o las reservas posibles, cuya recuperación es incierta.

5 Como ya se mencionó anteriormente, el extractivismo no solo se refiere a la extracción de petróleo o minerales, sino también a la extracción de otros recursos tales como la madera, los peces, el banano, el cacao, etcétera.

6 Salvo el caso que se concesione la extracción del recurso a empresas privadas, donde el Estado tiene que pagar a estas empresas ya sea con petróleo o con dinero por los servicios prestados.

7 Rentista se dice al país que basa sus ingresos en la extracción de recursos naturales y no en la producción de mercancías con valor agregado (manufacturas). El país rentista no se preocupa mucho en maxi- 
mizar el uso de sus ingresos porque sabe de antemano que el próximo año la naturaleza nuevamente le entregará con relativa facilidad más ingresos (TalCual, 2013).

8 El grado de industrialización es la relación porcentual entre el producto industrial y el producto interno bruto (PIB).

9 El deterioro de los términos de intercambio indica que los países exportadores de materias primas reciben un menor precio por sus productos en comparación con los países exportadores de manufacturas.

\section{REFERENCIAS}

Acosta, A. (2005). Desarrollo glocal: con la Amazonía en la mira. Quito, Ecuador: Corporación Editora Nacional.

Acosta, A. (2012a). Breve historia económica del Ecuador. Quito, Ecuador: Corporación Editora Nacional.

Acosta, A. (2012b). Extractivismo y neoextractivismo: dos caras de la misma maldición. En M. Lang y D. Mokrani (ed.), Más allá del desarrollo (pp. 84-118). Quito, Ecuador: Fundación Rosa Luxemburg/ Abya Yala.

Agencia Alemana de Cooperación Técnica. (2011). Pueblas indígenas en Ecuador. Recuperado de https:// www.giz.de/fachexpertise/downloads/giz2o11-es-laenderpapier-ecuador.pdf

Aguinaga, M., Lang, M., Mokrani, D. y Santillana, A. (2012). Pensar desde el feminismo: Críticas y alternativas al desarrollo. En M. Lang y D. Mokrani (ed.), Más allá del desarrollo (pp. 55-82). Quito, Ecuador: Fundación Rosa Luxemburg/Abya Yala.

Alvarado, R. (2014). Extractivismo y desarrollo. Quito, Ecuador: Flacso, Ecuador.

Banco Central del Ecuador. (2014). Producción exportación derivados 1972-2013. Quito, Ecuador: (s. d.).

Banco Central del Ecuador. (2018a). Indicadores económicos: deuda externa pública (\% del PIB). Recuperado de https://www.bce.fin.ec/index.php/informacioneconomica/

Banco Central del Ecuador. (2018b). Balanza de pagos normalizada. Recuperado de https://contenido. bce.fin.ec/documentos/Estadisticas/SectorExterno/BalanzaPagos/boletin62/indice.htm

Banco Mundial. (2018). Industria, valor agregado (\% del PIB). Recuperado de https://datos.bancomundial. org/indicador/NV.IND.TOTL.zs?end=2017\&start=1992\&year_high_desc=false

Cigüenza, N. (17 de junio de 2018). ¿Cómo el país con la mayor reserva de petróleo del mundo cayó en la ruina? La República. Recuperado de https://www.larepublica.co/especiales/venezuela-en-picada/ como-el-pais-con-la-mayor-reserva-de-petroleo-del-mundo-cayo-en-la-ruina-2739335

Cisneros, P. (2011). ¿Cómo se construye la sustentabilidad ambiental?: experiencias conflictivas de la industria minera en el Ecuador. Quito, Ecuador: Flacso, Ecuador.

Comisión Económica para América Latina y el Caribe (2018). La ineficiencia de la desigualdad. Recuperado de https://repositorio.cepal.org/bitstream/handle/11362/43442/ S1800059_es.pdf? sequence $=6$ \&isAllowed $=\mathrm{y}$

Comisión Económica para América Latina y el Caribe. (2016). América Latina y el Caribe es la región más desigual del mundo. ¿Cómo solucionarlo? Recuperado de https://www.cepal.org/fr/node/35842

Constitución de la República del Ecuador. (2008). Régimen del Buen Vivir. Manabí, Ecuador: Asamblea Nacional Constituyente.

Correa, R. (2015). Encuentro Somos Amazonía. Recuperado de http://www.presidencia.gob.ec/wp-content/uploads/downloads/2015/02/2015-02-03-SOMOSAMAZONIA.pdf

Ekos. (2015). La industria en Ecuador. Recuperado de http://www.ekosnegocios.com/negocios/verArticuloContenido.aspx?idArt $=6442$ 
El Telégrafo. (2014). La crisis bancaria de 1999 costó al país \$ 6.170 millones. Recuperado de https://www.eltelegrafo.com.ec/noticias/informacion/1/la-crisis-bancaria-de-1999-costo-al-pais-6-17o-millones

Federal Reserve System. (2014). Interest rate swaps: 1-year. Recuperado de http://www.federalreserve.gov/ releases/h15/data.htm

Fundación Regional de Asesoría en Derechos Humanos. (2016). Sarayaku: un caso emblemático de defensa territorial. Recuperado de https://www.inredh.org/index.php/noticias-inredh/ actualidad/384-sarayaku-un-caso-emblematico-de-defensa-territorial

Gudynas, E. (2012). Debates sobre el desarrollo y sus alternativas en América Latina: una breve guía heterodoxa. En M. Lang y D. Mokrani (ed.), Más allá del desarrollo (pp. 21-53). Quito, Ecuador: Fundación Rosa Luxemburg/Abya Yala.

Herrera, R. (2006). La teoría económica neoliberal y el desarrollo. Revista MR, 58(1), 38-50. Recuperado de http://www.iepala.es/IMG/pdf/La_teoria_economica_neoliberal_y_el_desarrollo-Remy_ Herrera.pdf

Instituto Nacional de Estadística y Censos (INEC). (2018a). Encuesta nacional de empleo, desempleo y subempleo (ENEMDU). Indicadores de pobreza y desigualdad: junio, 2018. Recuperado de http://www. ecuadorencifras.gob.ec/documentos/web-inec/POBREZA/2018/Junio-2018/201806_Pobreza.pdf

Instituto Nacional de Estadística y Censos (INEC). (2018b). Reporte de economía laboral: junio, 2018. Recuperado de http://www.ecuadorencifras.gob.ec/documentos/web-inec/EMPLEO/2018/Junio2018/Informe_Economia_laboral-jun18.pdf

Latouche, S. (2009). Pequeño tratado del Decrecimiento Sereno. Barcelona, España: Icaria Editorial s. A. Llanes, H. (2008). Contratos petroleros: inequidad en el reparto de la producción. Quito, Ecuador: (s. d.). Meadows, D., Meadows, D. y Randers, J. (1994). Más allá de los límites del crecimiento. Madrid, España: El País s. A./Aguilar s. A.

Ministerio de Industrias y Productividad. (2012). Ecuador aporta en construcción de nuevos paradigmas de desarrollo industrial. Recuperado de https://www.industrias.gob.ec/ ecuador-aporta-en-construccion-de-nuevos-paradigmas-de-desarrollo-industrial/

Ministerio de Relaciones Exteriores y Movilidad Humana. (2018). El caso Chevron / Texaco en Ecuador. Un lucha por la justicia ambiental y social. Recuperado de https://www.cancilleria.gob.ec/wpcontent/uploads/2015/o6/Expediente-Caso-Chevron-abril-2015.pdf

Ministerio del Ambiente. (2018). Mesa redonda sobre industria verde/crecimiento verde en la región de América Latina y el Caribe. Recuperado de http://www.ambiente.gob.ec/mesa-redonda-sobreindustria-verdecrecimiento-verde-en-la-region-de-america-latina-y-el-caribe/

Organización de las Naciones Unidas (ONU). (2018). Desarrollo sostenible. Recuperado de http://www. un.org/es/ga/president/65/issues/sustdev.shtml

Organización de Países Exportadores de Petróleo (opep). (2018). Annual Statistical Bulletin. Recuperado de https://asb.opec.org/

Pacheco, L. (2004). Política económica. Un enfoque desde la economía política. Quito, Ecuador: Letramía. Pacheco, M. (1 de marzo de 2018). Gobierno recibió informe sobre los subsidios de los combustibles. El Comercio. Recuperado de https://www.elcomercio.com/actualidad/carlosperez-gobierno-analiza-subsidios-combustibles.html

Prats, J. (2006). Teoría y práctica del desarrollo. Cambio en las variables de la ecuación del desarrollo en los últimos 50 años. Revista del CLAD Reforma y Democracia, (36), 1-17. Recuperado 
de http://old.clad.org/portal/publicaciones-del-clad/revista-clad-reforma-democracia/ articulos/036-octubre-2006/0054500

Primera, P. y Gregorio, J. (2013). La teoría económica del desarrollo desde Keynes hasta el nuevo modelo neoclásico del crecimiento económico. Revista Venezolana de Análisis de Coyuntura, 19(1), 123142. Recuperado de https://www.redalyc.org/pdf/364/36428605012.pdf

Ramírez, A., Sánchez, J. y García, A. (2004). El desarrollo sustentable: interpretación y análisis. Revista del Centro de Investigación de la Universidad La Salle, 6(21), 55-59. Recuperado de http://www. redalyc.org/articulo.oa?id=34202107

Roberts, L. (2010). El Ecuador en la época cacaotera. Quito, Ecuador: CODEu Editorial.

Schneyer, J. y Mora, N. (27 de noviembre de 2013). Reporte especial: Cómo China se apropió del petróleo de Ecuador. Plan V. Recuperado de http://www.planv.com.ec/investigacion/investigacion/ reporte-especial-como-china-se-apropio-del-petroleo-ecuador

Secretaría de Hidrocarburos. (2018). Informe de gestión: junio 2017-agosto 2018. Recuperado de http:// www.secretariahidrocarburos.gob.ec/wp-content/uploads/downloads/2018/o8/Informe-Fin-deGestio\%CC\%81n-Eco.-Francisco-Rendo\%CC\%81n.pdf

Sen, A. (2012). Desarrollo y libertad. Bogotá, Colombia: Planeta.

Statista. (2018). Evolución anual del precio medio del petróleo crudo fijado por la Organización de Países Exportadores de Petróleo (OPEP) de 1960 a 2018 (en dólares por barril). Recuperado de https:// es.statista.com/estadisticas/635114/precio-medio-del-crudo-fijado-por-la-opep/

Svampa, M. (diciembre de 2013). Consenso de los commodities, un debate actual. En J. Ponce (Presidencia), Desarrollo y ambiente. Simposio llevado a cabo en el vi Congreso Iberoamericano de Desarrollo y Ambiente, Quito, Ecuador.

TalCual. (2013). Economía rentista. Recuperado de http://www.talcualdigital.com/movil/visor. aspx?id=61689

Worm, B., Barbier, E., Beaumont, N., Duffy, J., Folke, C., Halpern, B. and Watson, R. (2006). Impacts of biodiversity loss on ocean ecosystem services. Science, (314), 787-79o. Recuperado de http://palumbi.stanford.edu/manuscripts/impacts\%20of\%2obiodiversity\%2oloss\%20on\%2oocean\%2o ecosystem\%2oservices.pdf 
